\title{
Physically Consistent Responses of the Global Atmospheric Hydrological Cycle in Models and Observations
}

\author{
Richard P. Allan • Chunlei Liu • Matthias Zahn • David A. Lavers • \\ Evgenios Koukouvagias • Alejandro Bodas-Salcedo
}

Received: 30 August 2012/ Accepted: 6 November 2012/Published online: 10 January 2013

(C) Springer Science+Business Media Dordrecht 2013

\begin{abstract}
Robust and physically understandable responses of the global atmospheric water cycle to a warming climate are presented. By considering interannual responses to changes in surface temperature $(T)$, observations and AMIP5 simulations agree on an increase in column integrated water vapor at the rate $7 \% / \mathrm{K}$ (in line with the Clausius-Clapeyron equation) and of precipitation at the rate $2-3 \% / \mathrm{K}$ (in line with energetic constraints). Using simple and complex climate models, we demonstrate that radiative forcing by greenhouse gases is currently suppressing global precipitation $(P)$ at $\sim-0.15 \% /$ decade. Along with natural variability, this can explain why observed trends in global $P$ over the period 1988-2008 are close to zero. Regional responses in the global water cycle are strongly constrained by changes in moisture fluxes. Model simulations show an increased moisture flux into the tropical wet region at $900 \mathrm{hPa}$ and an enhanced outflow (of smaller magnitude) at around $600 \mathrm{hPa}$ with warming. Moisture transport explains an increase in $P$ in the wet tropical regions and small or negative changes in the dry regions of the subtropics in CMIP5 simulations of a warming climate. For AMIP5 simulations and satellite observations, the heaviest 5-day rainfall totals increase in intensity at $\sim 15 \% / \mathrm{K}$ over the ocean with reductions at all percentiles over land. The climate change response in CMIP5 simulations shows consistent increases in $P$ over ocean and land for the highest intensities, close to the Clausius-Clapeyron scaling of $7 \% / \mathrm{K}$, while $P$ declines for the lowest percentiles, indicating that interannual variability over land may not be a good proxy for climate change. The local changes in precipitation and its extremes are highly dependent upon small shifts in the largescale atmospheric circulation and regional feedbacks.
\end{abstract}

Keywords Precipitation - Water - Climate models $\cdot$ Satellite data $\cdot$ Global change

R. P. Allan $(\varangle) \cdot$ C. Liu · M. Zahn · D. A. Lavers · E. Koukouvagias Department of Meteorology, National Centre for Atmospheric Sciences, University of Reading, Reading, UK

e-mail: r.p.allan@reading.ac.uk

A. Bodas-Salcedo

Met Office Hadley Centre, Exeter, UK 


\section{Introduction}

Recent occurrence of extreme weather across the globe (including flooding and drought) relates to shifts in atmospheric and oceanic circulation patterns (e.g., the mid-latitude jet stream or El Niño Southern Oscillation, ENSO) yet heightens concern upon the potential for human influence on and vulnerability to such events (e.g., Peterson et al. 2012). The frequency of damaging flooding and drought are projected to increase in the future based upon detailed computer simulations of the climate system (Meehl et al. 2007) and backed up by basic physics (Held and Soden 2006; O'Gorman et al. 2012); it is also vital that projected responses of the water cycle are verified, where possible, by careful use of homogeneous, well-characterized observations (Trenberth 2011).

The magnitude and rate of change in the regional hydrological cycle determine the impacts suffered by infrastructure, agriculture and health. The distribution of rainfall (in time and space), in particular for the extremes, is crucial in determining damage from particular events. Time and space means of hydrological quantities may reflect aspects of these changes, in particular for the amount of water potentially available for a region. However, the relevance of changes in global mean quantities to local impacts is unclear. Yet, without appreciation for the driving mechanisms at the largest spatial and temporal scales, the robust nature of local projections is questionable at best. In this paper, our aim is to identify the most important, robust and physically understandable responses in the atmospheric hydrological cycle, exploiting climate model simulations and confronting these with the globally available observational record.

\section{Constraints upon Global Mean Precipitation Responses}

The most robust climatic response to increasing temperatures is a rise in mean water vapor near to Earth's surface at $\sim 7 \% / \mathrm{K}$, in line with the Clausius-Clapeyron equation (see Sect. 2.3). Although changes in moisture are an important constraint upon regional changes in precipitation and its extremes (discussed in Sect. 3), it has been known for some time that the total amount of precipitation $(P)$ increases with warming at a slower rate than water vapor $(\sim 2-3 \% / \mathrm{K})$, responding instead to a changing heat balance of the atmosphere (Manabe and Wetherald 1975; Mitchell et al. 1987; Allen and Ingram 2002). The primary physical basis for this is that a warming atmosphere radiates energy away more effectively, particularly to the surface (e.g., Allan 2006; Stephens and Ellis 2008; Prata 2008).

To maintain energy balance in the atmosphere, this additional atmospheric net radiative cooling to space and to the surface $\left(\Delta Q_{\text {atm }}\right)$ is primarily compensated for by extra latent heating via precipitation $(L \Delta P)$ with changes in sensible heating of the atmosphere by the surface, $\Delta \mathrm{SH}$, playing a more minor role (but see Lu and Cai (2009)):

$$
L \Delta P=\Delta Q_{\mathrm{atm}}-\Delta \mathrm{SH},
$$

Surface evaporation $(E)$ is similarly constrained by energy balance; Richter and Xie (2008) find that climate models simulate small adjustments to boundary layer temperature, humidity and wind speed that cause $E$ to increase with warming below the rate expected from the Clausius-Clapeyron equation ( $\mathrm{Lu}$ and Cai 2009) and almost identically to the $P$ changes (as expected from the trivial moisture holding capacity of the atmosphere relative to the moisture fluxes).

As discussed by O'Gorman et al (2012), radiative cooling above the lifting condensation level is in fact more directly related to precipitation since, when heating is applied 
within the boundary layer, adjustments through SH do become important (e.g., Ming et al. 2010). For simplicity, we here assume that the balance between atmospheric radiative cooling and latent heating dominates. However, this simple balance between $\Delta P$ and $\Delta Q_{\text {atm }}(\Delta T)$ is complicated by a direct influence on atmospheric radiative cooling by the radiative forcings responsible for determining temperature response in the first place (Andrews et al. 2010; O'Gorman et al. 2012).

Global mean precipitation response, $\Delta P$, is determined by a "slow" component set by the global mean surface temperature change, $\Delta T$, (denoted slow since it takes a long time to heat up the oceans due to their dominating heat capacity) and a "fast" component $(f \Delta F)$ in which the atmosphere (with its small heat capacity relative to the ocean) rapidly adjusts to changes in top of atmosphere radiative forcing, $\Delta F$ (for simplicity, here defined as the downward radiative heating into the top of the atmosphere), that is independent of $\Delta T$ (Allen and Ingram 2002; Bala et al. 2010; Andrews et al. 2010; O'Gorman et al. 2012):

$$
L \Delta P \sim k \Delta T-f \Delta F .
$$

In (2), $L=2.5 \times 10^{6} \mathrm{~J} \mathrm{~kg}^{-1}$ is the latent heat of vaporization and $k \sim 2 \mathrm{~W} \mathrm{~m}^{-2} \mathrm{~K}^{-1}$ is the response of atmospheric radiative cooling to surface temperature, $\partial Q_{\mathrm{atm}} / \partial T$ (e.g., Allan 2006; Lambert and Webb 2008; Andrews et al. 2010), set by the atmospheric temperature and humidity lapse rates (e.g., moist adiabatic lapse rate with near-constant mean relative humidity is a reasonable approximation).

The fast scaling parameter, $f=\Delta F_{\text {atm }} / \Delta F$, is the instantaneous radiative forcing experienced by the atmosphere, $\Delta F_{\text {atm }}=-\Delta Q_{\mathrm{atm}}(\Delta F)$, normalized by the top of atmosphere radiative forcing $(\Delta F)$ and is specific to the nature of each radiative forcing component (Andrews et al. 2010; Ming et al. 2010). For example, increases in atmospheric $\mathrm{CO}_{2}$ concentrations produce an instantaneous increase in radiative forcing at the top of the atmosphere that is considerably larger than the increase in instantaneous (downward) radiative forcing at the surface, $\Delta F_{\text {sfc }}$ (e.g., Ramanathan 1981; Allan 2006), where $\Delta F=\Delta F_{\text {atm }}+\Delta F_{\text {sfc }}$. This causes a direct reduction in $\Delta P$ through the last term in (2), since $f_{\mathrm{CO}_{2}} \sim 0.8$ (Andrews et al. 2010) and a slower increase in $\Delta P$ through the resulting rises in $\Delta T$ brought about by the positive radiative forcing. The timescale for $k \Delta T$ is increased for smaller ocean heat uptake and a more positive overall climate feedback (see also McInerney and Moyer 2012). The interaction between these two effects is fundamental in determining the transient response of $\Delta P$ to $\Delta F$, or hydrological sensitivity (Ming et al. 2010).

\subsection{Simple Model of Global Precipitation}

To illustrate the global constraint upon $\Delta P$, a simple zero-dimensional energy budget model is employed, based upon the approach of Hansen et al. (1981). A mixed-layer ocean temperature perturbation $\Delta T_{\mathrm{m}}$ is computed as

$$
\frac{\mathrm{d} \Delta T_{\mathrm{m}}}{\mathrm{d} t}=\frac{1}{C_{\mathrm{m}}}\left(\Delta F-Y \Delta T_{\mathrm{m}}-D\right),
$$

where $C_{\mathrm{m}}=4.218 \times 10^{8} \mathrm{~J} \mathrm{~K}^{-1} \mathrm{~m}^{-2}$ is the ocean mixed-layer heat capacity, $Y=1.3 \mathrm{~W} \mathrm{~m}^{-2} \mathrm{~K}^{-1}$ is the climate feedback parameter, and

$$
D=c\left(\Delta T_{\mathrm{m}}-\Delta T_{\mathrm{D}}\right) / d,
$$

is the diffusion of energy into the deep ocean $\left(d=500 \mathrm{~m}, c=421.8 \mathrm{~W} \mathrm{~K}^{-1} \mathrm{~m}^{-1}\right)$ where deep ocean temperature, $\Delta T_{\mathrm{D}}$ is determined by $\mathrm{d} \Delta T_{\mathrm{D}} / \mathrm{d} t=D / C_{\mathrm{D}}$, where $C_{\mathrm{D}}=3.7962 \times$ 
(a) Radiative Forcings

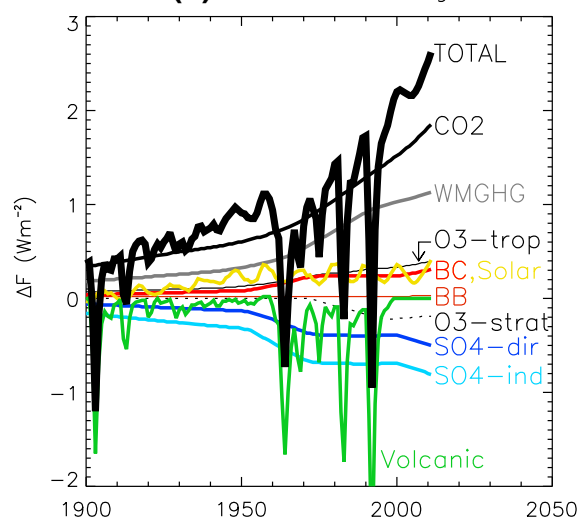

(c) Surface Temperature

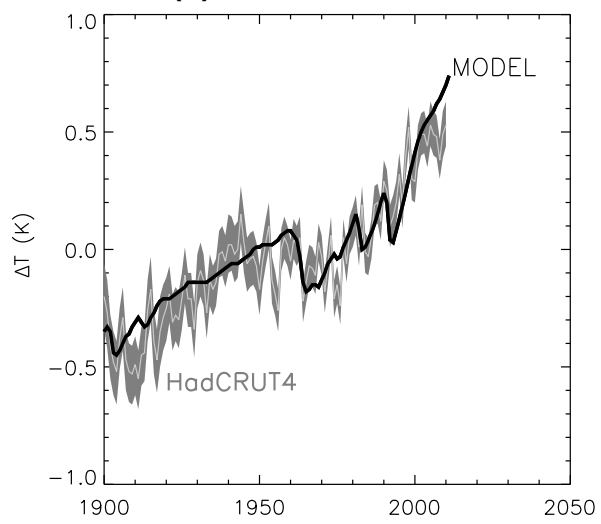

(b) Atmospheric Heating

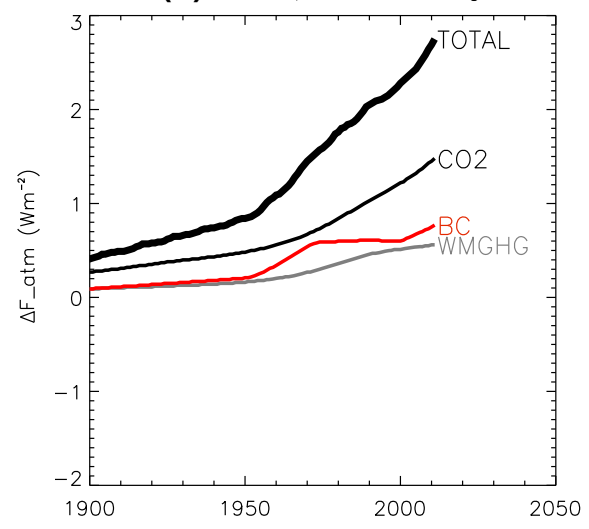

(d) Precipitation

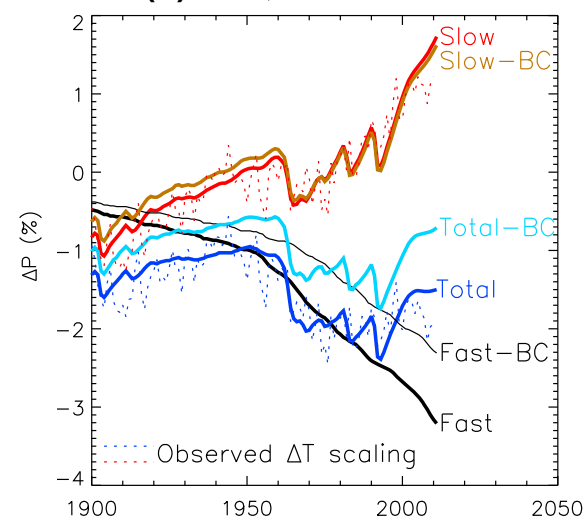

Fig. 1 Changes in a radiative forcings $(\Delta F)$, b atmospheric radiative heating $\left(\Delta F_{\text {atm }}\right)$ due to the top of atmosphere radiative forcings using scaling factors from Andrews et al. (2010), c simulated temperature response using a simple energy balance model compared with HadCRUT4 observations (95\% uncertainty range) and $\mathbf{d}$ precipitation response $(\Delta P)$ using the simple energy balance model decomposed into fast and slow components ("-BC" denotes simulations without the effects of Black Carbon aerosol). In d, observed slow response is also estimated using the HadCRUT4 $\Delta T$; this is combined with the model fast responses to provide an estimated total scaling (dotted lines)

$10^{9} \mathrm{~J} \mathrm{~K}^{-1} \mathrm{~m}^{-2}$ is the deep ocean heat capacity. Thus, $\Delta T_{\mathrm{m}}$ is determined by the radiative forcing, the restoring flux relating to feedbacks, and diffusion of energy into the deep ocean.

Observed $\Delta F$ is prescribed over the period 1850-2010, based upon the Model for the Assessment of Greenhouse gas-Induced Climate Change (MAGICC) without carbon cycle for anthropogenic forcings, ${ }^{1}$ and natural forcings are based upon the Goddard Institute for Space Studies $^{2}$ (e.g., Hansen et al. 2007) with simple extrapolation of some fields from 1990 onward (Fig. 1a). The model is initialized at 1850 as $\Delta T_{\mathrm{m}}=\Delta T_{\mathrm{D}}=0$. Since the

\footnotetext{
1 http://www.cgd.ucar.edu/cas/wigley/magicc/.

${ }^{2}$ http://data.giss.nasa.gov/modelforce/.
} 
Table 1 Prescribed values of atmospheric forcing scaling parameter $f=\Delta F_{\text {atm }} / \Delta F$

\begin{tabular}{ccccccccc}
\hline Forcing & $\mathrm{CO}_{2}$ & Other WMGHG & $\mathrm{O}_{3}$ trop. & $\mathrm{O}_{3}$ strat. & $\mathrm{SO}_{4}$ (all) & $\mathrm{BB}$ & $\mathrm{BC}$ & Solar \\
\hline$f$ & 0.8 & 0.5 & -0.3 & 0.0 & 0.0 & -0.9 & 2.5 & 0.2 \\
\hline
\end{tabular}

Well-Mixed Greenhouse Gases (WMGHG) includes $\mathrm{CH}_{4}, \mathrm{~N}_{2} \mathrm{O}$ and $\mathrm{CFCs} ; \mathrm{SO}_{4}$ includes all sulfate aerosol forcings (direct, indirect and volcanic). $B B$ biomass burning aerosol, $B C$ black carbon aerosol

purpose of this analysis is illustrative only, inaccuracies in the prescribed radiative forcings and other model parameters are not considered a serious impediment.

To compute $\Delta P$ using our simple model, we combine (2) with (3-4) where $f$ is prescribed as in Table 1 and assuming that $\Delta T \equiv \Delta T_{\mathrm{m}}$. Thus, $\Delta F_{\mathrm{atm}}$ is computed from $\Delta F$ at each 1 year time step (Fig. 1b); forcing agents that do not interact with the atmosphere (e.g., purely scattering $\mathrm{SO}_{4}$ aerosol) are assumed not to influence the fast $\Delta P$ responses. The model simulated $\Delta T$ is depicted in Fig. 1c and compares favorably with observed estimates from the HadCRUT4 observations (Morice et al. 2012). The fast and slow ( $T$-dependent) components of $\Delta P$ are computed from (2) using the model simulated $\Delta T$ and $\Delta F_{\text {atm }}$ in Fig. 1d. Also shown are estimates neglecting the fast response from Black Carbon aerosol (-BC) and prescribing the HadCRUT4 $\Delta T$ for the slow component (dotted lines).

The slow $\Delta P$ component rises with $\Delta T$ at the rate $2 \mathrm{~W} \mathrm{~m}^{-2} \mathrm{~K}^{-1}$, as prescribed by the parameter $k$, and is relatively insensitive to the inclusion of $\mathrm{BC}$ aerosol or error in simulated $\Delta T$ (although the recent hiatus in global temperature rises since $\sim 2000$ are not captured). The fast component leads to reduced $\Delta P$, which is enhanced by the inclusion of $\mathrm{BC}$ (additional atmospheric absorption of radiative energy leading to atmospheric stabilization and declining global $\Delta P$ ). Overall, the total $\Delta P$ response shows little global trend, consistent with recent observationally based estimates (Adler et al. 2008), although responses to volcanic forcings can introduce apparent trends over decadal timescales. Inaccuracies in the model parameters, including the scaling factors, $k$ and $f$, will reduce the realism of the simple model estimates. It is, therefore, instructive to progress from the simple model on to the considerably more detailed depiction of global precipitation changes simulated by coupled climate model simulations.

\subsection{Transient Response in Global Precipitation in CMIP5 Models}

The simulated transient climate response is illustrated in Fig. 2 which shows $\Delta P$ simulated by fully coupled climate models (see details in Table 2) as part of the Coupled Model Intercomparison Project-phase 5 (CMIP5; Taylor et al. 2011). Fig. 2a shows increases in $\Delta P$ over the twenty-first century, rising by around 3-11\% over the period 2000-2100. The RCP8.5 (Representative Concentration Pathways) scenario (an emissions pathway leading to a radiative forcing of $8.5 \mathrm{~W} \mathrm{~m}^{-2}$ by 2100) simulates a larger response than the more mitigating RCP4.5 scenario (as illustrated by the thick ensemble mean lines) although there is considerable inter-ensemble spread. This is partly explained by the larger $\Delta T$ response simulated by RCP8.5 as illustrated in Fig. 2b. A simple linear fit between $\Delta P$ and $\Delta T$ produces a sensitivity of $\sim 1 \% / \mathrm{K}$; this is smaller than implied by the scaling parameter $k$ in (2) since rising greenhouse gas concentrations are muting the overall $\Delta P$ response to warming by heating the atmosphere.

For each scenario, there is also a large inter-model spread, since models with higher climate sensitivities (and/or slower rates of ocean heat uptake) tend to warm more rapidly 

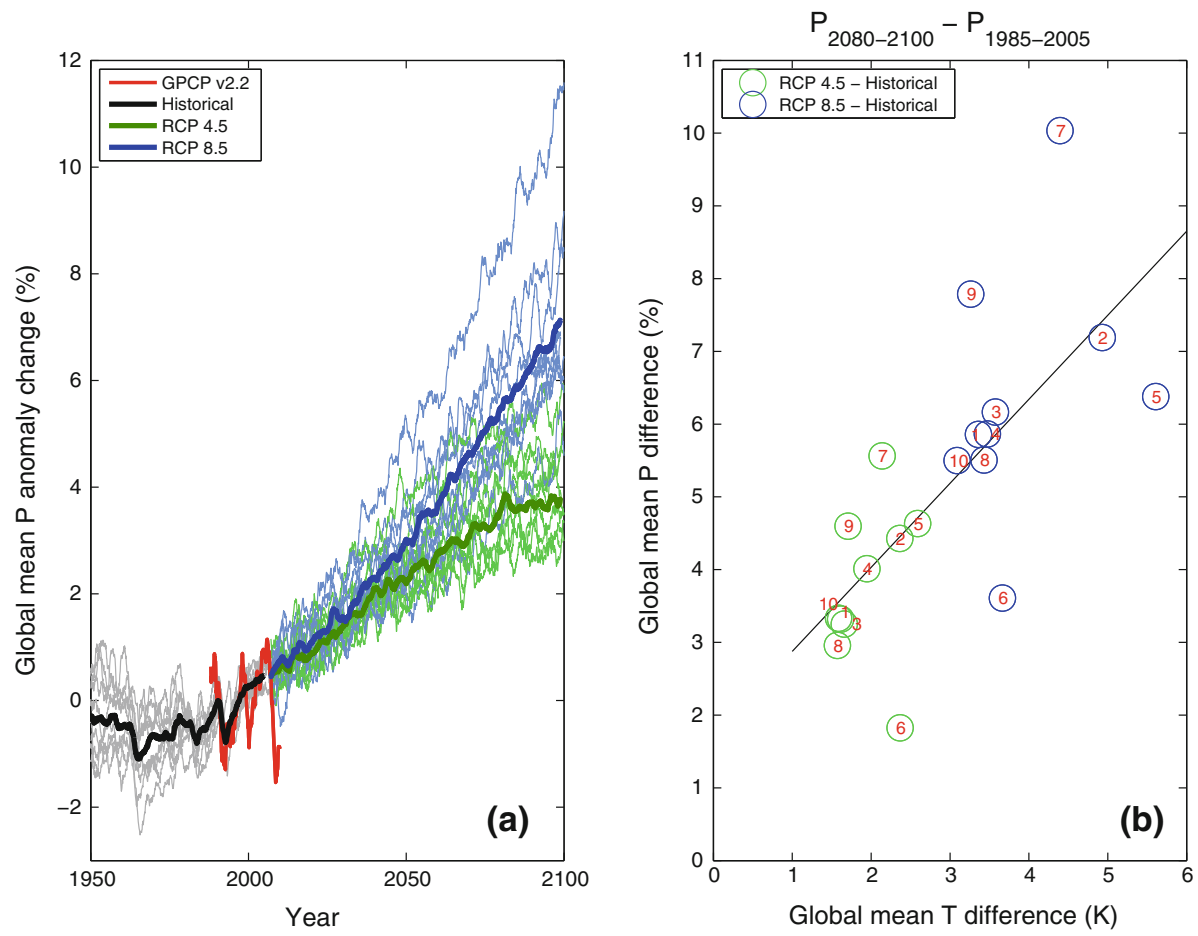

Fig. 2 a Changes in global mean precipitation (relative to 1988-2005) for CMIP5 climate simulations (RCP4.5 and RCP8.5 future projections relative to the parent simulation from the historical simulations, models 1-10 in Table 2). Observationally based GPCP precipitation anomalies are plotted for comparison. Twenty-four month running means are applied. b 2080-2100 minus 1985-2005 global mean precipitation change plotted relative to changes in global mean surface temperature for RCP4.5-historical and RCP8.5historical simulations. Model numbers in Table 2 are displayed, and a line of best fit to these values is shown in black

and therefore increase $P$ through the slow response term in (2). However, the relationship between $\Delta T$ and $\Delta P$ is not robust, particularly for the RCP8.5 scenario; this may be explained by the fact that the RCP8.5 scenario is far from equilibrium by 2100 (e.g., McInerney and Moyer 2012), while the model simulations in the RCP4.5 scenario are showing signs of a levelling off in $\Delta P$ (as $\Delta F \rightarrow 4.5 \mathrm{~W} \mathrm{~m}^{-2}$ after $\sim 2060$ ). The INMCM4 model simulates a muted $\Delta P / \Delta T$ response relative to other models, while the IPSLCM5A-LR and MRI-CGCM3 models simulate a slightly larger $\Delta P / \Delta T$ response relative to the other models (see Table 2 for definition of climate models). As noted, the actual $\Delta P$ is also related to the direct influence of the radiative forcings upon atmospheric radiative cooling (Andrews et al. 2010) while the timescale for change in $\Delta T$ is lengthened for models with weaker ocean heat uptake and more positive feedback (e.g., Hansen et al. 2011). The contribution of natural variability, model diversity and scenario uncertainty to precipitation projections is discussed further, in the context of the older CMIP3 model simulations, by Hawkins and Sutton (2011)

To investigate the direct influence of radiative forcing on transient climate change, a present-day AMIP5 simulation (observed sea surface temperature, SST, and sea ice distribution are prescribed over the period 1979-2008) of the atmospheric component of the 
Table 2 Details of CMIP5 climate models simulations employed

\begin{tabular}{lll}
\hline Modelling centre & Model & References \\
\hline $\begin{array}{l}\text { (1) Beijing Climate Center } \\
\text { (2) Canadian Centre for Climate Modelling } \\
\text { and Analysis }\end{array}$ & BCC-CSM1-1 & Wu et al. (2012) \\
(3) National Center for Atmospheric Research, USA & CCSM4 & Arora et al. (2011) \\
(4) Centre National de Recherches & CNRM-CM5 & Gent et al. (2011) \\
Meteorologiques, France & & Voldoire et al. (2012) \\
(5) Met Office Hadley Centre, UK & HadGEM2-ES & Collins et al. (2011) \\
& HadGEM2-A & \\
(6) Institute for Numerical Mathematics, Russia & INMCM4 & Volodin et al. (2010) \\
(7) Institut Pierre Simon Laplace, France & IPSL-CM5A-LR & Hourdin et al. (2012) \\
(8) Max Planck Institute for Meteorology, Germany & MPI-ESM-LR & Raddatz et al. (2007) \\
(9) Meteorological Research Institute, Japan & MRI-CGCM3 & Yukimoto et al. (2012) \\
(10) Norwegian Climate Centre & NorESM1-M & Zhang et al. (2012) \\
(11) Model for Interdisciplinary Research on & MIROC5 & Watanabe et al. (2010) \\
Climate, Japan & &
\end{tabular}

Hadley Centre Global Environment Model version 2 (HadGEM2) model (Collins et al. 2011) is conducted. A standard Atmospheric Models Intercomparison Project (AMIP5) control run is used (CTL), in which realistic radiative forcings are prescribed, and compared with an identical simulation but with greenhouse gases fixed at their 1978 levels (fGHG).

Figure 3a shows declining CTL minus fGHG global mean clear-sky outgoing longwave radiation, OLRc (dOLRc/d $t=-0.37 \mathrm{~W} \mathrm{~m}^{-2} / \mathrm{dec}, r=-0.79$ ). This is explained by the rising greenhouse gas concentrations in CTL (e.g., Allan 2006; Chung and Soden 2010) which reduce the longwave radiative cooling of the atmosphere to space. A decreasing trend in total (all-sky) atmospheric net radiative cooling to space and to the surface (Fig. 3b) is less marked ( $\left.\mathrm{d} Q_{\mathrm{atm}} / \mathrm{d} t=-0.13 \mathrm{~W} \mathrm{~m}^{-2} / \mathrm{dec}, r=-0.32\right)$ since the presence of high-altitude cloud masks the enhanced greenhouse effect of rising $\mathrm{CO}_{2}$ concentrations in CTL. There are also substantial differences associated with differing internal variability between experiments; this also explains most of the differences in $P$ between CTL and fGHG (Fig. 3c), but a declining trend is also discernible $(\mathrm{d} P / \mathrm{d} t=-0.15 \% / \mathrm{dec} \sim-$ $\left.0.14 \mathrm{~W} \mathrm{~m}^{-2} / \mathrm{dec}, r=-0.25\right)$. The clear correlation between $\Delta Q_{\mathrm{atm}}$ and $\Delta P(r=0.66)$ is physically reasonable and primarily explained by internal variability differences between simulations with only a small, yet detectable, fraction relating to the $\mathrm{CO}_{2}$ trend.
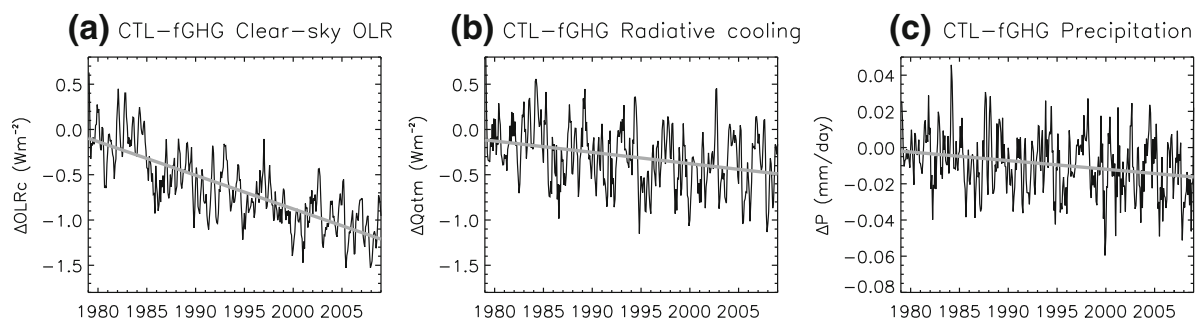

Fig. 3 Global mean differences in a clear-sky outgoing longwave radiation (OLR), b net all-sky atmospheric radiative cooling and c precipitation for HadGEM2-A AMIP5 simulations with observed greenhouse gases (CTL) and fixed greenhouse gases (fGHG) with least squares fit trend lines. A 3-month box-car average is applied to the time series 
This simple experiment illustrates that the direct radiative effect of rising greenhouse gas concentrations is muting current trends in global $P$ but that the influences may be difficult to isolate from natural variability in the present-day climate. We now examine in more detail how well simulations can capture current changes in the global hydrological cycle.

\subsection{Current Changes in the Global Atmospheric Water Cycle}

Observationally based estimates of global precipitation changes in Fig. 2a from the Global Precipitation Climatology Project (GPCP), which combines infrared and microwave satellite data over the ocean with infrared and rain-gauge observations over land (Huffman et al. 2009), show substantial variability but little discernible trend, consistent with the simple model results described in Fig. 1. Current changes in the global atmospheric water cycle are now examined in more detail.

Figure $4 \mathrm{a}-\mathrm{b}$ shows that, on interannual timescales, global mean column integrated water vapor $(W)$ is strongly coupled with $T$ both in model simulations (here AMIP5 simulations with specified observed SST and sea ice) and in observations (combined microwave satellite data $^{3}$ over ocean between $50^{\circ} \mathrm{S}-50^{\circ} \mathrm{N}$ and ERA Interim reanalysis simulations ${ }^{4}$ elsewhere) and also from the HadCRUH surface specific humidity $(q)$ dataset (Willett et al. 2008). Table 3 shows that $W$ rises at $\sim 7 \% / \mathrm{K}$ when considering interannual variability over the period 1988-2008, similar to the Clausius-Clapeyron rate as previously demonstrated (Wentz and Schabel 2000; Willett et al. 2008). Correlation between SSM/I-ERA Interim $W$ and independent HadCRUH $q$ over the period 1989-2003 is remarkable $(r=0.86)$.

Reanalyses remain unable to adequately simulate global changes in the hydrological cycle (e.g., Trenberth et al. 2011; John et al. 2009) as illustrated by the changes in $W$ and $P$ in Fig. 4b-c. This primarily relates to changes in the observing system over the ocean (Dee et al. 2011). Nevertheless, changes in $T$ globally and $W$ over land are thought to be reasonable (Simmons et al. 2010) as are the simulated interannual changes in top of atmosphere net radiation (Loeb et al. 2012) and within the atmosphere as depicted in Fig. 4d. The satellite-based ISCCP (Zhang et al. 2004) and Surface Radiation Budget (SRB) (Stackhouse Jr. et al. 2011) estimates of $Q_{\text {atm }}$ suffer from inaccurate changes in surface fluxes, for example clear-sky surface longwave fluxes over land.

While coupled model simulations in Fig. 2a appear to underestimate the observed GPCP variability, this is not the case for AMIP simulations in Fig. 4c. There is good agreement for the positive interannual $\mathrm{d} P / \mathrm{d} T$ relationship between GPCP and AMIP5 over the period 1988-2008 (Table 3) although the robust nature of changes in precipitation from satellite data over the ocean remains questionable prior to 1995 (Liu et al. 2012). It is nevertheless encouraging that a global relationship between $Q_{\mathrm{atm}}$ from ERA Interim and $P$ from GPCP emerges, broadly consistent with model simulations and close to unity (Table 3) as anticipated from physical grounds (O'Gorman et al. 2012).

\footnotetext{
3 We use Scanning Multi-channel Microwave Radiometer (SMMR) and the Special Sensor Microwave Imager $(\mathrm{SSM} / \mathrm{I})$ data that provide ocean retrievals of $W$ and also ocean retrievals of $P$ from the SSM/I instruments on the F08/F11/F13 series of Defense Meteorological Satellite Program platforms (e.g., Wentz and Schabel 2000; John et al. 2009).

${ }^{4}$ Reanalyses combine weather forecast model simulations with available observations using data assimilation to provide a 3-dimensional depiction of atmospheric properties, usually every 6 hours. The European Centre for Medium-range Weather Forecasts (ECMWF) Interim reanalysis, ERA Interim, is a state of the art reanalysis system covering the period 1979 to present, which for example assimilates vertical temperature and humidity information from satellite and conventional observations. A detailed description is given by Dee et al. (2011).
} 

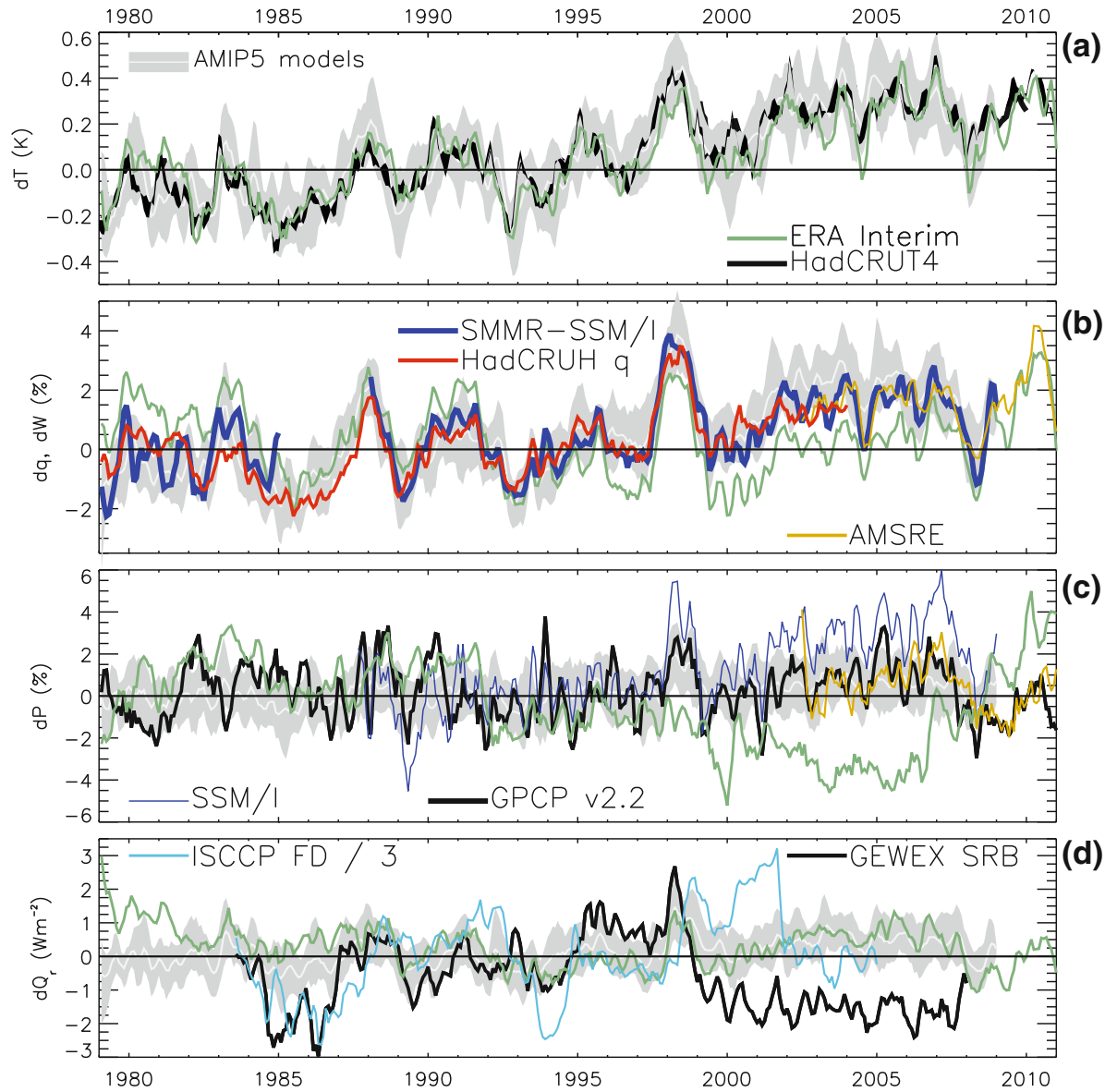

Fig. 4 Deseasonalized anomalies in a surface air temperature, b column integrated water vapor or specific humidity, $\mathbf{c}$ precipitation and $\mathbf{d}$ atmospheric net radiative cooling for AMIP5 simulations ( \pm 1 inter-model standard deviation, models 2 and 4-11 in Table 2) and observationally based estimates. All time series anomalies are relative to the 1988-1996 base period (models are adjusted relative to the ensemble mean) apart from SMMR (1983/1984 base period) and Advanced Microwave Scanning Radiometer-EOS (AMSRE) (mean adjusted to agree with mean SSM/I $W$ and GPCP $P$ over the period 2003-2008); 3-month averages of anomalies are plotted. In a, the $95 \%$ uncertainty range is shown for HadCRUT4 observations. In b and $\mathbf{c}$, the SMMR and SSM/I record uses the satellite microwave record over the $50^{\circ} \mathrm{S}-50^{\circ} \mathrm{N}$ oceans and ERA Interim $W$ or GPCP $P$ data elsewhere. In d, the International Satellite Cloud Climatology Project - Flux Dataset (ISCCP-FD) atmospheric radiative cooling anomalies are reduced by a factor of 3

Trends documented in Table 3 cover too short a record (1988-2008) to be physically meaningful yet provide a useful comparison between AMIP5 simulations and observations. Rapid warming from 1993-2002 ( 0.4 K), after the eruption of Mt. Pinatubo in 1991, is followed by static global mean $T$; it has been suggested that a shift in ocean circulation may have contributed to this variability (e.g., Merrifield 2011; Gu and Adler 2012). A rise in $W$ over 1988-2008 of around $1 \%$ /decade from SSM/I-ERA Interim and simulations is equivalent to $\sim 5-6 \% / \mathrm{K}$ given the trend in $T$, slightly lower than anticipated from Clausius-Clapeyron. Trends in global $P$ (Table 3 ) are not statistically significant over the period, consistent with expectations from the simple model in Sect. 2.1 However, 
Table 3 Relationship between global water vapor, temperature, precipitation and radiative cooling and their trends based on linear regression over the 1988-2008 deseasonalized time series

\begin{tabular}{lllll}
\hline Variables & $y$ & $x$ & $\mathrm{~d} y / \mathrm{d} x$ & $r$ \\
\hline $\mathrm{d} W / \mathrm{d} T$ & SSM/I-ERAINT & HadCRUT4 & $6.42 \pm 0.46 \% / \mathrm{K}$ & $0.84^{* \#}$ \\
& AMIP5 & AMIP5 & $7.14 \pm 0.24 \% / \mathrm{K}$ & $0.96^{* \#}$ \\
$\mathrm{~d} P / \mathrm{d} T$ & GPCP & HadCRUT4 & $2.83 \pm 0.92 \% / \mathrm{K}$ & $0.32^{* \#}$ \\
& AMIP5 & AMIP5 & $2.52 \pm 0.22 \% / \mathrm{K}$ & $0.79^{* \#}$ \\
$\mathrm{~d} Q_{\mathrm{atm}} / \mathrm{d} T$ & ERAINT & ERAINT & $2.50 \pm 0.29 \mathrm{~W} \mathrm{~m}^{-2} / \mathrm{K}$ & $0.68^{* \#}$ \\
& AMIP5 & AMIP5 & $1.92 \pm 0.16 \mathrm{~W} \mathrm{~m}^{-2} / \mathrm{K}$ & $0.79^{* \#}$ \\
$\mathrm{~d} P / \mathrm{d} Q_{\text {atm }}$ & GPCP & ERAINT & $1.09 \pm 0.17$ & $0.57^{* \#}$ \\
& AMIP5 & AMIP5 & $0.83 \pm 0.03$ & $0.95^{* \#}$ \\
$\mathrm{~d} T / \mathrm{d} t$ & HadCRUT4 & & $0.18 \pm 0.02 \mathrm{~K} / \mathrm{dec}$ & $0.70^{* \#}$ \\
& AMIP5 & & $0.18 \pm 0.02 \mathrm{~K} / \mathrm{dec}$ & $0.66^{\#}$ \\
$\mathrm{~d} W / \mathrm{d} t$ & SSM/I-ERAINT & & $0.84 \pm 0.20 \% / \mathrm{dec}$ & $0.42^{\#}$ \\
& AMIP5 & & $1.17 \pm 0.18 \% / \mathrm{dec}$ & $0.59^{\#}$ \\
$\mathrm{~d} P / \mathrm{d} t$ & GPCP & & $0.18 \pm 0.25 \% / \mathrm{dec}$ & 0.08 \\
& AMIP5 & & $0.34 \pm 0.09 \% / \mathrm{dec}$ & 0.40 \\
\hline
\end{tabular}

* Significant at the $95 \%$ level allowing for autocorrelation; ${ }^{*}$ correlations significant at the $95 \%$ confidence level assuming 20 degrees of freedom

ERAINT is the ECMWF Interim reanalysis

normalizing by $\mathrm{d} T / \mathrm{d} t$ gives a sensitivity of $1-2 \% / \mathrm{K}$, slightly lower than the interannual relationship, $\mathrm{d} P / \mathrm{d} T \sim 2-3 \% / \mathrm{K}$, and consistent with the influence of greenhouse gases on supressing global rainfall via fast responses described in Sect. 2.2. The $\mathrm{d} P / \mathrm{d} t$ response when using SSM/I data over the oceans is larger than the GPCP only product (Fig. 4c). Wentz et al. (2007) previously calculated a $\mathrm{d} P / \mathrm{d} T$ sensitivity of $6 \% / \mathrm{K}$ over the period 1987-2006; the short length of this record, calibration uncertainty and lack of a mechanism for removing the extra latent heat associated with large increases in $P$ would suggest that this is not a good proxy for the longer term response of $P$ to warming.

\section{Water Vapor and Regional Constraints on Precipitation}

While global mean $\Delta P$ is found to rise in climate model projections, the changes are not uniformly distributed across the globe. As outlined by Meehl et al. (2007) in a warming climate, there is a tendency for

- the wet regions (inter-tropical convergence zones and higher latitudes) to become wetter and the dry subtropical regions drier,

- an increase in the intensity of precipitation over most continental regions,

- an increase in occurrence of consecutive dry days over many lower latitude regions.

This is broadly consistent with results from early climate model experiments (e.g., Manabe and Wetherald 1980; Mitchell et al. 1987) and implies more damaging flooding and drought in a warmer world (Trenberth 2011). Although there are large regions of the globe for which the sign of future projections of $\Delta P$ are ambiguous (Meehl et al. 2007), some of these regions are likely to experience only small $\Delta P$ relative to natural variability (Power et al. 2011). The physical basis for these projections is now discussed. 


\subsection{Moisture Flux into Tropical Wet Regions}

Water vapor exerts a powerful physical constraint on the global water cycle. It provides a strongly positive feedback to climate change (Manabe and Wetherald 1967; Soden et al. 2005; Willett et al. 2008; Ingram 2010) but also controls the atmospheric temperature lapse rate and modulates radiative cooling (e.g., O'Gorman et al. 2012) and is central to the large-scale regional responses in precipitation. In the broadest sense, water is transported in the atmosphere by the tropical circulation from the dry, subtropical oceans (net moisture divergence) to the wet, moisture convergence zones, and also to the higher latitudes (e.g., Bengtsson et al. 2011) and the continents (e.g., Trenberth et al. 2011). Rising $W$ with warming (Table 3) therefore indicates increased moisture flux $\left(M_{\mathrm{F}}\right)$. Assuming that the magnitude of changes in atmospheric moisture storage is negligible compared with the other terms, a simple moisture balance dictates that $M_{\mathrm{F}}$ balances precipitation minus evaporation $(P-E)$ :

$$
P-E \sim M_{\mathrm{F}} .
$$

Assuming, for now, that wind flows are unchanged, $M_{\mathrm{F}}$ will simply vary with atmospheric moisture, at the rate $\alpha \sim 7 \% / \mathrm{K}$ (Table 3). In fact, to reconcile the energetic constraints upon global precipitation with the thermodynamic contraints upon water vapor, climate models simulate a weakening of the tropical Walker circulation that is also evident in observations and simulations of the twentieth century (Vecchi et al. 2006), while decadal variability may cause temporary increases in the Walker circulation (Sohn et al. 2012). Nevertheless, as argued by Held and Soden (2006), the simple assumptions in (5) imply an enhancement of $P-E$ patterns in climate model simulations (at least over the ocean where moisture supply is unlimited) with warming

$$
\delta(P-E) \sim-\nabla \cdot\left(\alpha \delta T M_{\mathrm{F}}\right) \sim \alpha \delta T(P-E) .
$$

This effect is illustrated in Fig. 5 which shows the changes in $M_{\mathrm{F}}$ from the dry regions (column mean downward vertical motion) to the wet regions (column mean upward vertical motion) of the tropics defined by 6-hourly instantaneous fields (Zahn and Allan 2011). $M_{\mathrm{F}}$ is computed at each vertical level along the line dividing wet and dry regions.
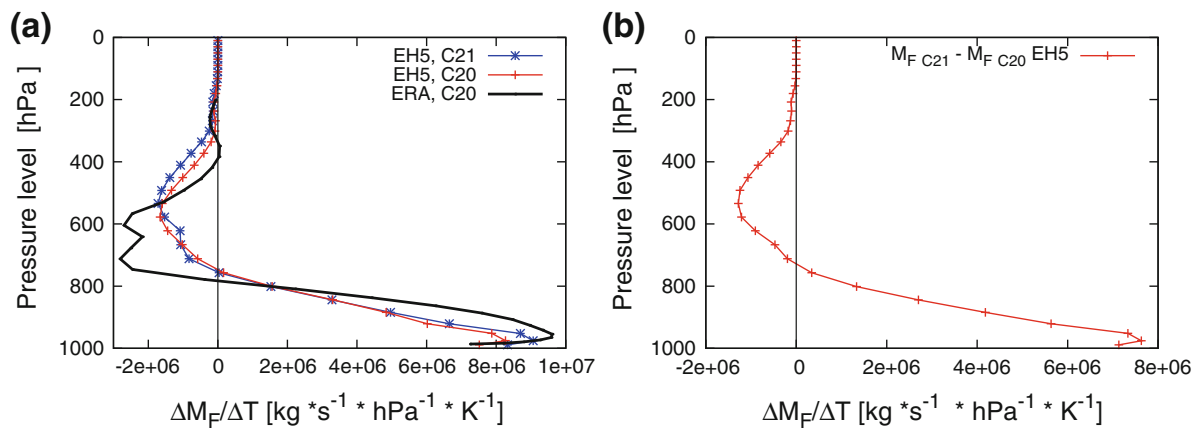

Fig. 5 Change in moisture flux from the dry to the wet regions of the tropics per $\mathrm{K}$ change in surface temperature between a warm and cold months in ERA Interim and ECHAM5 (twentieth and twenty-first centuries time slices) and for $\mathbf{b}$ the climate change response from twenty-first minus twentieth century simulated by ECHAM5 (EH5). In a, moisture fluxes were computed separately for months with above and below average tropical mean surface temperature; in forming the mean, each month of the year was ascribed equal weighting. For the climate change response, the mean moisture fluxes were calculated and differenced between (21C, 2069-2099) and (20C, 1959-1989) 
Changes in $M_{\mathrm{F}}$ normalized by $\Delta T[\mathrm{~kg} /(\mathrm{s} \mathrm{hPa} \mathrm{K})]$ between cold and warm months are plotted for ERA Interim in Fig. 5a. This shows increased inflow at low levels (maximum at $\sim 950 \mathrm{hPa}$ ), but a significant compensating increase in mid-level outflow at around 600$700 \mathrm{hPa}$ as discussed by Zahn and Allan (2011). A similar response is evident for twentieth century (20C, 1959-1989) and twenty-first century (21C, 2069-2099) time slice simulations from a high resolution $\left(0.5^{\circ}\right)$ climate model, ECHAM5 (Roeckner et al. 2003), as described by Zahn and Allan (2012). However, the model simulations indicate a higher altitude for the maximum changes in moisture outflow and less vertical structure, which may be influenced by the higher vertical resolution below altitudes of $500 \mathrm{hPa}$ in ERA Interim. Back and Bretherton (2006) suggest that meridional SST gradients determine the altitude of outflow regionally and the nature of the differences in Fig. 5a merits future analysis. Also shown in Fig. $5 \mathrm{~b}$ is the $21 \mathrm{C}$ minus $20 \mathrm{C}$ change in $M_{\mathrm{F}}$ into the wet region of the tropics, normalized by $\Delta T=3.0 \mathrm{~K}$. The vertical structure of the climate change response of $M_{\mathrm{F}}$ is very similar to interannual variability shown in Fig. 5a where year to year changes in $T$ are relatively small $(\Delta T \sim 0.6 \mathrm{~K})$.

\subsection{Precipitation Response in the Wet and Dry Regions of the Tropics}

It does not simply follow from (6) that $P$ rises in the wet regions and declines in the dry regions. Nevertheless, since $\Delta E$ changes are expected to be more spatially uniform than $\Delta P$ changes, there is a strong expectation that the wet regions will become wetter and the dry regions drier in the tropics, borne out by recent analysis of climate models (e.g., Chou et al. 2009) and limited observational evidence (e.g., Allan et al. 2010).

Figure 6 demonstrates that climate models indeed simulate an increase in $P$ in the wet regions $(>70$ th percentile of $P$ ordered by intensity, defined each month such that the precise location of the wet region varies with time) and static or declining $P$ in other (dry) regions of the tropics. This definition of wet and dry regimes is based upon the analysis of Allan et al. (2010) but is somewhat arbitrary. Mean $P$ is about $8 \mathrm{~mm} /$ day in the wet regions while the remaining regions are not completely dry $(P \sim 1 \mathrm{~mm} /$ day $)$. GPCP observations (displayed since 1988 due to inhomogeneities before this date when SSM/I data was not available) also show this contrasting wet/dry response as discussed by Liu et al. (2012). Since this response is contingent on warming (enhancing $P-E$ ), this explains the flattening off of $P$ responses in the RCP4.5 simulations after around 2060 as $T$ asymptotes. Nevertheless, as discussed previously, the precise transient $\Delta P$ response is strongly influenced by the fast forcing processes $(f \Delta F)$ in addition to the slow response to warming, $k \Delta T$ (Andrews and Forster 2010; Wu et al. 2010).

\subsection{Extremes of Precipitation}

Within the wet regions, during heavy rainfall events, the atmosphere is typically precipitating more water over the course of a day than is contained in the atmospheric column at a particular location; this underlines the vital role of moisture convergence in determining intense rainfall rates (e.g., Trenberth 2011). While low-level moisture changes are indeed thought to provide a strong constraint upon $P$ intensification in a warming world, changes in updraft velocity with warming explain the large range in simulated responses in the tropics (e.g., O'Gorman and Schneider 2009; Allan et al. 2010; Sugiyama et al. 2010). Observed relationships provide a powerful constraint upon future simulated responses in extreme precipitation (O'Gorman 2012). Figure 7 displays observed and simulated 
Tropical $\left(30^{\circ} \mathrm{S}-30^{\circ} \mathrm{N}\right)$
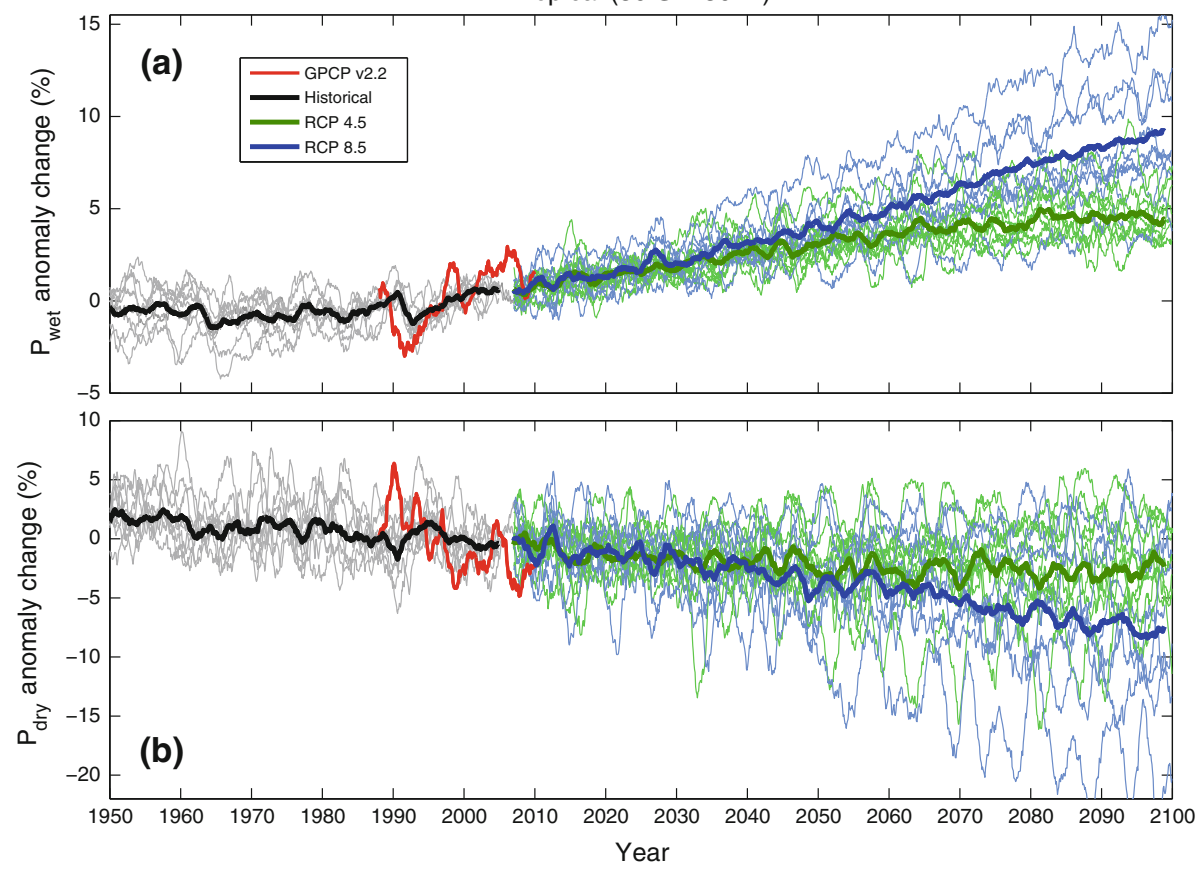

Fig. 6 Changes in tropical $\left(30^{\circ} \mathrm{S}-30^{\circ} \mathrm{N}\right)$ mean precipitation $(\%)$ in a the wet regions (above the 70 th percentile of monthly precipitation) and in $\mathbf{b}$ the dry regions (below the 70th percentile) relative to the 1988-2005 period for the historical, RCP4.5 and RCP8.5 scenario simulations (thick lines denote 10-model ensemble means, models 1-10 in Table 2) and the GPCP observations. A 24-month running mean is applied

precipitation responses, as a function of precipitation intensity $\left(P_{\mathrm{i}}\right)$, for the present day and also the simulated climate change responses.

The 5-day $P$ averages are constructed, and a deseasonalized intensity $(i)$ distribution constructed each month; 5-day averages are chosen to avoid structural inconsistencies between data sets that occur at higher time resolutions (Liu and Allan 2012). The linear regression of $P_{\mathrm{i}}$ is computed with respect to tropical mean $T$ (deseasonalized anomalies) and normalized by mean $P_{\mathrm{i}}$ to give units of $\% / \mathrm{K}$. Figure $7 \mathrm{a}$ illustrates the intensification of $P$ at the 99th percentile in both AMIP5 simulations and GPCP 1 Degree Daily (DD) V1.1 daily observations (Huffman et al. 2009) of around $15 \% / \mathrm{K}$, larger than expected from Clausius-Clapeyron scaling. At the lowest percentiles, $P_{\mathrm{i}}$ decreases with tropic-wide warming, consistent with the monthly mean responses shown in Fig. 6.

The GPCP 1DD observations generally show a similar but more positive response than the AMIP5 simulations (Fig. 7a), explained primarily by ocean regions, for $P_{\mathrm{i}<99 \%}$ (Fig. 7b). The SSM/I observations display a more positive sensitivity still for these percentiles and do not capture the decline in $P_{\mathrm{i}<60 \%}$ with warming. This may be explained by the limited sampling of low rain rates by the instantaneous overpasses (e.g., Liu and Allan 2012). GPCP gauge-based observations and AMIP5 simulations display remarkable agreement over the land (Fig. 7c), consistent with monthly mean variability (Liu et al. 2012); for $P_{\mathrm{i}<99 \%}$ the response is negative and explained by ENSO variability: during warmer El Niño years, there is less rainfall on average over land (e.g., Gu et al. 2007). 

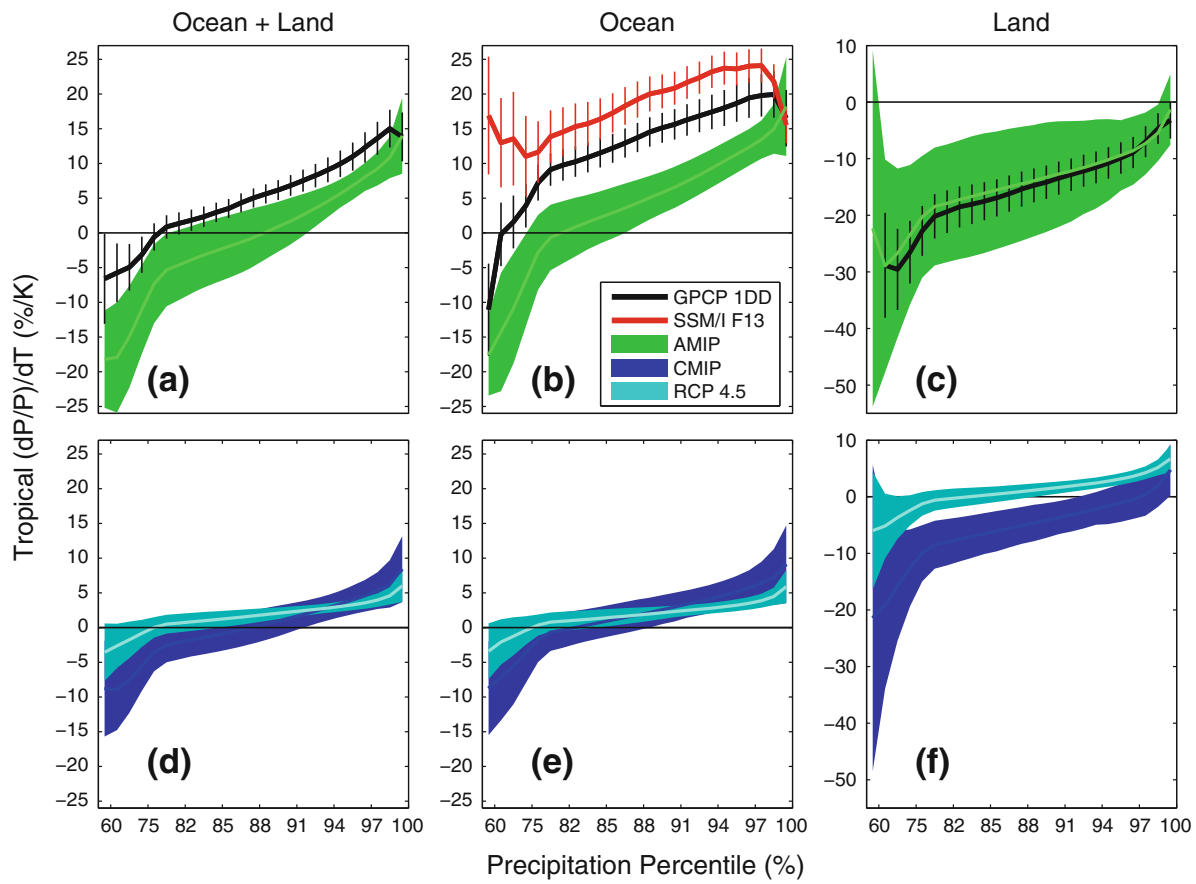

Fig. 7 Percentage responses of 5-day mean $P$ to changes in tropical $\left(30^{\circ} \mathrm{S}-30^{\circ} \mathrm{N}\right)$ mean $T$ as a function of $P$ intensity percentiles in the present day (1998-2008, linear regression) for a the tropics, $\mathbf{b}$ tropical ocean and $\mathbf{c}$ tropical land for AMIP5, GPCP 1DD and SSM/I and for the present and future in CMIP5 models (historical 1985-2005 using linear regression) and RCP4.5 minus historical (2080-2100 minus 1985-2005 using differences in mean intensity distribution) for the $\mathbf{d}$ tropics, $\mathbf{e}$ tropical ocean and $\mathbf{f}$ tropical land. In all cases, tropical (land and ocean) mean $T$ is used. Shaded areas denotes \pm 1 standard deviation of inter-model spread; vertical bars denote \pm 1 standard error in the linear regression for GPCP and SSM/I. Models 1-10 in Table 2 are used

The climate change response of 5-day $P$ extremes is compared with present-day simulations from the historical experiments in Fig. 7d-f. Consistent with the AMIP5 simulations and observations, there is a tendency for the wet percentiles to become wetter during warm months, while the dry percentiles become drier (Fig. 7d). Statistical uncertainty is large for $P_{\mathrm{i}<60 \%}$ over land (Fig. 7f), a likely result of the small and zero $P$ totals in this bin. The tropic-wide percentile responses in Fig. $7 \mathrm{~d}$ are dominated by the ocean regions (Fig. 7e). However, the climate change response (calculated as a percentile distribution difference between 2080 and 2099 RCP4.5 minus 1985-2005 historical simulations) displays a more modest response compared with the present-day linear regression applied to CMIP5 historical simulations (which are only slightly weaker than the AMIP5 simulations and observed relationships). The climate change response indicates a $P_{99 \%}$ response of $\sim 6 \% / \mathrm{K}$, close to that expected from the Clausius-Clapeyron relation.

For land regions, the climate change response of $P_{\mathrm{i}}$ to warming is more positive than the present-day CMIP5 relationships (Fig. 7f) with $P_{99 \%}$ responses out to 2080-2100 again close to that anticipated from Clausius-Clapeyron scaling. Thus, relationships derived from present-day variability are not good proxies for the climate change responses, in particular for the land regions. This is because ENSO variability enhances ocean $P$ sensitivity to warming and cooling, due to changing rainfall patterns, while it introduces a 
(a) AMIP5 14 Oct $2008 \mathrm{q}(\mathrm{g} / \mathrm{kg})$

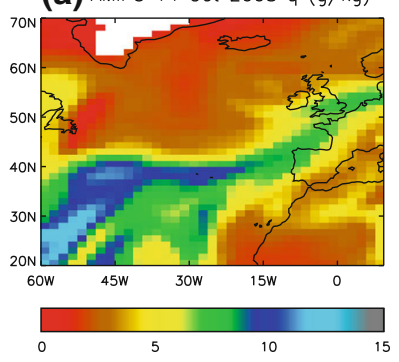

(b) RCP85 5 Jan $2009 \mathrm{q}(\mathrm{g} / \mathrm{kg})$

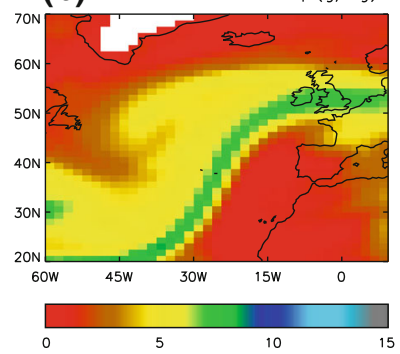

(C) RCP85 14 Nov $2097 \mathrm{q}(\mathrm{g} / \mathrm{kg})$

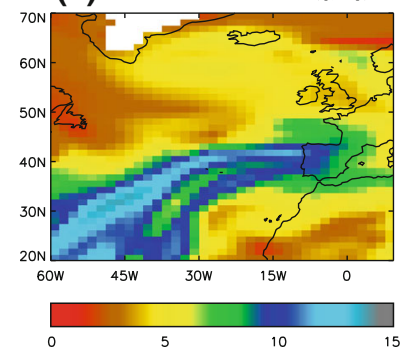

Fig. 8 Specific humidity $(q)$ fields at $850 \mathrm{hPa}$ associated with the highest 3-day precipitation total for grid boxes within the UK region $\left(7^{\circ} \mathrm{W}-3^{\circ} \mathrm{E}, 50-60^{\circ} \mathrm{N}\right)$ during the winter-half year (October-March) for a HadGEM2-A AMIP simulations (1995-2008) and HadGEM2-ES RCP8.5 simulations over the periods b 2006-2019 and c 2085-2098

negative relationship between $P$ and $T$ over land (Gu et al. 2007; Liu et al. 2012). The climate change responses are consistent with an intensification of $P$ at high percentiles, close to the water vapor responses of around $6 \% / \mathrm{K}$, and reduced $P$ for the dry regions (sub-tropical anticyclonic regimes) of net moisture export (e.g., Allan 2012), consistent with Fig. 6.

\subsection{Influence of Dynamical Changes on Precipitation and Its Extremes}

At finer time and space scales, it is less clear what the precise response of extreme precipitation to warming will be (Haerter et al. 2010). While the Clausius-Clapeyron relation provides a broad constraint, additional local latent heating may invigorate storms leading to a super-Clausius-Clapeyron scaling (Lenderink et al. 2011) while moisture limitation and atmospheric stabilization associated with latent heating at larger scales may result in responses below that anticipated from Clausius-Clapeyron (Haerter et al. 2010). Knowledge of the precise time and space scales associated with the most damaging flooding events is therefore crucial.

Changes in updraft velocity strongly influence the simulated $P_{99.9} \%$ response in the tropics (Turner and Slingo 2009; O'Gorman and Schneider 2009; Allan et al. 2010); the heaviest rainfall events are reliant on parametrized processes operating below the model grid scale. At higher latitudes, where large-scale processes become dominant in explaining intense precipitation, the simulated responses show greater consistency (O'Gorman and Schneider 2009) although there is evidence that they underestimate the observed responses (Min et al. 2011). In the UK, peak river flows during the winter-half of the year have been found to be associated with Atmospheric Rivers (Lavers et al. 2011). These are long $(\sim 1,000 \mathrm{~km})$, narrow $(\sim 100 \mathrm{~km})$ regions of strong water vapor transport in the warm sector of extra-tropical cyclones that can result in intense rainfall when the moisture is condensed, in particular following the uplift of the moisture-laden air-masses over mountains (e.g., Dettinger et al. 2011).

Atmospheric reanalyses, such as ERA Interim, and current climate models are typically able to resolve the large-scale processes associated with these flood-inducing events. Figure 8 illustrates the specific humidity $(q)$ structure associated with 14-year maximum 3-day $P$ totals for grid points around the UK for present-day simulations and future projections. The present-day simulations are indeed associated with Atmospheric River structures. The future projection in Fig. 8c simulates greater amounts of water vapor, consistent with 
warmer $T$, but the dynamical structure is unlike the present-day cases and in fact delivers a smaller 3-day $P$ total $(112 \mathrm{~mm})$ than the present-day event simulated in Fig. $8 \mathrm{~b}(152 \mathrm{~mm})$. While this is just an illustration, it nevertheless highlights the potential importance of both dynamical and thermodynamic factors in influencing future changes in extreme rainfall. The thermodynamic climate change component of such events is likely to be robust with the Clausius-Clapeyron relation a reliable constraint. However, small changes in the jet stream and storm track regions (and the overall dynamical character of intense rainfall-producing events) may dominate the local response and therefore regional projections of the occurrence of damaging flooding and drought remain a substantial challenge.

\section{Conclusions}

Global precipitation is projected to rise in the future primarily to maintain balance with enhanced atmospheric radiative cooling as temperatures increase (Manabe and Wetherald 1975). This slow, well-constrained response of around $\sim 2-3 \% / \mathrm{K}$ is modulated by more rapid adjustments to the radiative forcings, that are themselves responsible for current and future warming, but which directly influence atmospheric radiative cooling (Andrews et al. 2010). An additional influence appears to relate to how far from equilibrium the climate system is (McInerney and Moyer 2012). This is governed by the differing timescales of adjustment by the land and ocean and the associated changes in energy and moisture fluxes between them (Cao et al. 2012).

Regional changes in the hydrological cycle, of more importance for climate impacts, are more strongly tied to (i) changes in moisture transports which are well constrained by the Clausius-Clapeyron equation linking saturation vapor pressure with temperature and (ii) small spatial movements in large-scale circulation systems which are highly uncertain. This also applies to the local, extreme precipitation events which are strongly linked to the rises in low-level moisture of around $7 \% / \mathrm{K}$ but are also influenced by changes in the nature and spatial distribution of intense rainfall events.

The combination of the global changes in precipitation of around $\sim 2-3 \% / \mathrm{K}$ and increased low-level moisture of $\sim 7 \% / \mathrm{K}$ leads to a general trend toward the wet regions (Inter Tropical Convergence Zone and higher latitudes) becoming wetter and the dry subtropics getting drier. In the margins, although projected responses appear ambiguous, there are physical grounds for anticipating relatively small changes in $P$, signifying a greater consensus on regional projections than previously thought (Power et al. 2011). Nevertheless, local changes are highly dependent upon small shifts in position of largescale atmospheric circulation patterns and in the physical nature of rainfall regimes, in particular for extremes. Hence, determining accurate responses in the hydrological cycle at the scales required for impact models may be beyond the predictive capacity of climate modelling. Thus, determining robust, large-scale, robust responses in the hydrological cycle (e.g., Martin 2012) remain a crucial tool in understanding and planning for a changing water cycle in the future.

Acknowledgments The comments and suggestions of Paul O'Gorman and two anonymous reviewers helped to improve the paper. This work was undertaken as part of the PAGODA and PREPARE projects funded by the UK Natural Environmental Research Council under grants NE/I006672/1 and NE/G015708/1 and was supported by the National Centre for Earth Observations and the National Centre for Atmospheric Science. A. Bodas-Salcedo was supported by the Joint DECC/Defra Met Office Hadley Centre Climate Programme (GA01101). GPCP v2.2 data were extracted from http://precip.gsfc.nasa.gov/gpcp_v2.2_data. html, and CMIP5 and AMIP5 data sets from the British Atmospheric Data Centre (http://badc.nerc.ac.uk/ 
home) and the Program for Climate Model Diagnosis and Intercomparison: pcmdi3.llnl.gov/esgcet. We acknowledge the World Climate Research Programme's Working Group on Coupled Modelling, which is responsible for CMIP, and we thank the climate modelling groups (models listed in Table 2) for producing and making available their model outputs; for CMIP, the U.S. Department of Energy's PCMDI provided coordinating support and led development of software infrastructure in partnership with the Global Organization for Earth System Science Portals. The scientists involved in the generation of these data sets are sincerely acknowledged. We thank also Prof Keith Shine for developing the zero-dimensional climate model.

\section{References}

Adler RF, Gu G, Wang JJ, Huffman GJ, Curtis S, Bolvin D (2008) Relationships between global precipitation and surface temperature on interannual and longer timescales (1979-2006). J Geophys Res 113:D22104. doi:10.1029/2008JD010536

Allan RP (2006) Variability in clear-sky longwave radiative cooling of the atmosphere. J Geophys Res 111:D22105. doi:10.1029/2006JD007304

Allan RP (2012) Regime dependent changes in global precipitation. Clim Dyn 39:827-840. doi:10.1007/ s00382-011-1134-X

Allan RP, Soden BJ, John VO, Ingram WI, Good P (2010) Current changes in tropical precipitation. Environ Res Lett 5:025205. doi:10.1088/1748-9326/5/2/025205

Allen MR, Ingram WJ (2002) Constraints on future changes in climate and the hydrologic cycle. Nature 419:224-232

Andrews T, Forster PM (2010) The transient response of global-mean precipitation to increasing carbon dioxide levels. Environ Res Lett 5:025212. doi:10.1088/1748-9326/5/2/025212

Andrews T, Forster PM, Boucher O, Bellouin N, Jones A (2010) Precipitation, radiative forcing and global temperature change. Geophys Res Lett 37:L14701. doi:10.1029/2010GL043991

Arora VK, Scinocca JF, Boer GJ, Christian JR, Denman KL, Flato GM, Kharin VV, Lee WG, Merryfield WJ (2011) Carbon emission limits required to satisfy future representative concentration pathways of greenhouse gases. Geophys Res Lett 38:L05805. doi:10.1029/2010GL046270

Back LE, Bretherton CS (2006) Geographic variability in the export of moist static energy and vertical motion profiles in the tropical Pacific. Geophys Res Lett 33:L17810. doi:10.1029/2006GL026672

Bala G, Caldeira K, Nemani R (2010) Fast versus slow response in climate change: implications for the global hydrological cycle. Clim Dyn 35:423-434. doi:10.1007/s00382-009-0583-y

Bengtsson L, Hodges KI, Koumoutsaris S, Zahn M, Keenlyside N (2011) The changing atmospheric water cycle in Polar Regions in a warmer climate. Tellus A 63:907-920. doi:10.1111/j.1600-0870.2011. 00534.X

Cao L, Bala G, Caldeira K (2012) Climate response to changes in atmospheric carbon dioxide and solar irradiance on the time scale of days to weeks. Environ Res Lett 7:034015. doi:10.1088/1748-9326/7/3/ 034015

Chou C, Neelin JD, abd J-Y Tu CAC (2009) Evaluating the "rich get richer" mechanism in tropical precipitation change under global warming. J Clim 22:1982-2005

Chung ES, Soden BJ (2010) Radiative signature of increasing atmospheric carbon dioxide in HIRS satellite observations. Geophys Res Lett 37:L07707. doi:10.1029/2010GL042698

Collins WJ, Bellouin N, Doutriaux-Boucher M, Gedney N, Halloran P, Hinton T, Hughes J, Jones CD, Joshi M, Liddicoat S, Martin G, O’Connor F, Rae J, Senior C, Sitch S, Totterdell I, Wiltshire A, Woodward S (2011) Development and evaluation of an earth-system model-HadGEM2. Geosci Model Dev Discuss 4:997-1062. doi:10.5194/gmdd-4-997-2011

Dee DP, Uppala SM, Simmons AJ, Berrisford P, Poli P, Kobayashi S, Andrae U, Balmaseda MA, Balsamo G, Bauer P, Bechtold P, Beljaars ACM, van de Berg L, Bidlot J, Bormann N, Delsol C, Dragani R, Fuentes M, Geer AJ, Haimberger L, Healy SB, Hersbach H, Hólm EV, Isaksen L, Kållberg P, Köhler M, Matricardi M, McNally AP, Monge-Sanz BM, Morcrette JJ, Park BK, Peubey C, de Rosnay P, Tavolato C, Thépaut JN, Vitart F (2011) The ERA-Interim reanalysis: configuration and performance of the data assimilation system. Q J Roy Meteorol Soc 137:553-597. doi:10.1002/qj.828

Dettinger MD, Ralph FM, Das T, Neiman PJ, Cayan DR (2011) Atmospheric rivers, floods and the water resources of California. Water 3:445-478. doi:10.3390/w3020445

Gent PR, Danabasoglu G, Donner LJ, Holland MM, Hunke EC, Jayne SR, Lawrence DM, Neale RB, Rasch PJ, Vertenstein M, Worley PH, Yang ZL, Zhang M (2011) The community climate system model version 4. J Clim 24:4973-4991. doi:10.1175/2011JCLI4083.1 
Gu G, Adler RF (2012) Interdecadal variability/long-term changes in global precipitation patterns during the past three decades: global warming and/or pacific decadal variability? Clim Dyn. doi:10.1007/ s00382-012-1443-8

Gu G, Adler RF, Huffman GJ, Curtis S (2007) Tropical rainfall variability on interannual-to-interdecadal and longer time scales derived from the GPCP monthly product. J Clim 20:4033-4046

Haerter JO, Berg P, Hagemann S (2010) Heavy rain intensity distributions on varying time scales and at different temperatures. J Geophys Res 115:D17102

Hansen J, Johnson D, Lacis A, Lebedeff S, Lee P, Rind D, Russell G (1981) Climate impact of increasing atmospheric carbon dioxide. Science 213:957-966. doi:10.1126/science.213.4511.957

Hansen J, Sato M, Ruedy R, Kharecha P, Lacis A, Miller R, Nazarenko L, Lo K, Schmidt GA, Russell G, Aleinov I, Bauer S, Baum E, Cairns B, Canuto V, Chandler M, Cheng Y, Cohen A, Del Genio A, Faluvegi G, Fleming E, Friend A, Hall T, Jackman C, Jonas J, Kelley M, Kiang NY, Koch D, Labow G, Lerner J, Menon S, Novakov T, Oinas V, Perlwitz J, Perlwitz J, Rind D, Romanou A, Schmunk R, Shindell D, Stone P, Sun S, Streets D, Tausnev N, Thresher D, Unger N, Yao M, Zhang S (2007) Climate simulations for 1880-2003 with GISS modelE. Clim Dyn 29:661-696. doi:10.1007/ s00382-007-0255-8

Hansen J, Sato M, Kharecha P, von Schuckmann K (2011) Earth's energy imbalance and implications. Atmos Chem Phys 11:13421-13449. doi:10.5194/acp-11-13421-2011

Hawkins E, Sutton R (2011) The potential to narrow uncertainty in projections of regional precipitation change. Clim Dyn 37:407-418. doi:10.1007/s00382-010-0810-6

Held IM, Soden BJ (2006) Robust responses of the hydrological cycle to global warming. J Clim 19:5686-5699

Hourdin F, Grandpeix JY, Rio C, Bony S, Jam A, Cheruy F, Rochetin N, Fairhead L, Idelkadi A, Musat I, Dufresne JL, Lahellec A, Lefebvre MP, Roehrig R (2012) LMDZ5B: the atmospheric component of the IPSL climate model with revisited parameterizations for clouds and convection. Clim Dyn. doi: 10.1007/s00382-012-1343-y

Huffman GJ, Adler RF, Bolvin DT, Gu G (2009) Improving the global precipitation record: GPCP version 2.1. Geophys Res Lett 36:L17808. doi:10.1029/2009GL040000

Ingram W (2010) A very simple model for the water vapour feedback on climate change. Q J R Meteorol Soc 136:30-40. doi:10.1002/qj.546

John VO, Allan RP, Soden BJ (2009) How robust are observed and simulated precipitation responses to tropical warming. Geophys Res Lett 36:L14702. doi:10.1029/2009GL038276

Lambert FH, Webb MJ (2008) Dependency of global mean precipitation on surface temperature. Geophys Res Lett 35:L16706. doi:10.1029/2008GL034838

Lavers DA, Allan RP, Wood EF, Villarini G, Brayshaw DJ, Wade AJ (2011) Winter floods in Britain are connected to atmospheric rivers. Geophys Res Lett 38:L23803. doi:10.1029/2011GL049783

Lenderink G, Mok HY, Lee TC, van Oldenborgh GJ (2011) Scaling and trends of hourly precipitation extremes in two different climate zones-Hong Kong and The Netherlands. Hydrol Earth Syst Sci 15:3033-3041. doi:10.5194/hess-15-3033-2011

Liu C, Allan RP (2012) Multisatellite observed responses of precipitation and its extremes to interannual climate variability. J Geophys Res 117:D03101. doi:10.1029/2011JD016568

Liu C, Allan RP, Huffman GJ (2012) Co-variation of temperature and precipitation in CMIP5 models and satellite observations. Geophys Res Lett 39:L13803. doi:10.1029/2012GL052093

Loeb NG, Lyman JM, Johnson GC, Allan RP, Doelling DR, Wong T, Soden BJ, Stephens GL (2012) Observed changes in top-of-the-atmosphere radiation and upper-ocean heating consistent within uncertainty. Nat Geosci 5:110-113. doi:10.1038/ngeo1375

Lu J, Cai M (2009) Stabilization of the atmospheric boundary layer and the muted global hydrological cycle response to global warming. J Hydrometeorol 10:347-352. doi:10.1175/2008JHM1058.1

Manabe S, Wetherald RT (1967) Thermal equilibrium of the atmosphere with a given distribution of relative humidity. J Atmos Sci 24:241-259

Manabe S, Wetherald RT (1975) The effects of doubling the $\mathrm{CO}_{2}$ concentration on the climate of a general circulation model. J Atmos Sci 32:3-15

Manabe S, Wetherald RT (1980) On the distribution of climate change resulting from an increase in $\mathrm{CO}_{2}$ content in the atmosphere. J Atmos Sci 37:99-118

Martin G (2012) Quantifying and reducing uncertainty in the large-scale responses of the water cycle. Surv Geophys (accepted) doi:10.1007/s10712-012-9203-1

McInerney D, Moyer E (2012) Direct and disequilibrium effects on precipitation in transient climates. Atmos Chem Phys Discuss 12:19649-19681. doi:10.5194/acpd-12-19649-2012

Meehl G, Stocker T, Collins W, Friedlingstein P, Gaye A, Gregory J, Kitoh A, Knutti R, Murphy J, Noda A, Raper S, Watterson I, Weaver A, Zhao ZC (2007) Global climate projections. Climate change 2007: 
the physical science basis. Contribution of working group I to the fourth assessment report of the Intergovernmental Panel on Climate Change, Cambridge University Press, Cambridge, pp 747-845

Merrifield MA (2011) A shift in western tropical Pacific Sea level trends during the 1990s. J Clim 24:4126-4138 doi:10.1175/2011JCLI3932.1

Min S, Zhang X, Zwiers FW, Hegerl GC (2011) Human contribution to more-intense precipitation extremes. Nature 470:378-381

Ming Y, Ramaswamy V, Persad G (2010) Two opposing effects of absorbing aerosols on global-mean precipitation. Geophys Res Lett 37:L13701

Mitchell J, Wilson CA, Cunnington WM (1987) On $\mathrm{CO}_{2}$ climate sensitivity and model dependence of results. Q J Roy Meteorol Soc 113:293-322

Morice CP, Kennedy JJ, Rayner NA, Jones PD (2012) Quantifying uncertainties in global and regional temperature change using an ensemble of observational estimates: the HadCRUT4 data set. J Geophys Res 117:D08101. doi:10.1029/2011JD017187

O'Gorman PA (2012) Sensitivity of tropical precipitation extremes to climate change. Nat Geosci 5:697-700 doi:10.1038/ngeo1568

O'Gorman PA, Schneider T (2009) The physical basis for increases in precipitation extremes in simulations of 21st-century climate change. Proc Nat Acad Sci 106:14773-14777

O'Gorman PA, Allan RP, Byrne MP, Previdi M (2012) Energetic constraints on precipitation under climate change. Surv Geophys 33:585-608. doi:10.1007/s10712-011-9159-6

Peterson TC, Stott PA, Herring S (2012) Explaining extreme events of 2011 from a climate perspective. Bull Am Meteorol Soc 93:1041-1067. doi:10.1175/BAMS-D-12-00021.1

Power SB, Delage F, Colman R, Moise A (2011) Consensus on twenty-first-century rainfall projections in climate models more widespread than previously thought. J Clim 25:3792-3809

Prata F (2008) The climatological record of clear-sky longwave radiation at the earth's surface: evidence for water vapour feedback? Int J Remote Sens 29:5247-5263. doi:10.1080/01431160802036508

Raddatz TJ, Reick CH, Knorr W, Kattge J, Roeckner E, Schnur R, Schnitzler KG, Wetzel P, Jungclaus J (2007) Will the tropical land biosphere dominate the climate-carbon cycle feedback during the twentyfirst century? Clim Dyn 29:565-574. doi:10.1007/s00382-007-0247-8

Ramanathan V (1981) The role of ocean-atmosphere interactions in the $\mathrm{CO}_{2}$ climate problem. J Atmos Sci 38:918-930

Richter I, Xie SP (2008) The muted precipitation increase in global warming simulations: a surface evaporation perspective. J Geophys Res 113:D24118. doi:10.1029/2008JD010561

Roeckner E, Bäuml G, Bonaventura L, Brokopf R, Esch M, Giorgetta M, Hagemann S, Kirchner I, Kornblueh L, Manzini E, Rhodin A, Schlese U, Schulzweida U, Tompkins A (2003) The atmospheric general circulation model ECHAM 5. Part I: model description. Technical report 349, 140 pp, MaxPlank institüte für Meteorologie, Hamburg

Simmons AJ, Willett KM, Jones PD, Thorne PW, Dee DP (2010) Low-frequency variations in surface atmospheric humidity, temperature, and precipitation: inferences from reanalyses and monthly gridded observational data sets. J Geophys Res 115:D01110. doi:10.1029/2009JD012442

Soden BJ, Jackson DL, Ramaswamy V, Schwarzkopf MD, Huang X (2005) The radiative signature of upper tropospheric moistening. Science 310:841-844

Sohn BJ, Yeh SW, Schmetz J, Song HJ (2012) Observational evidences of Walker circulation change over the last 30years contrasting with GCM results. Clim Dyn 1-12. doi:10.1007/s00382-012-1484-Z

Stackhouse PW Jr, Gupta SK, Cox SJ, Zhang T, Mikovitz JC, Hinkelman LM (2011) 24.5-year srb data set released. GEWEX News 21:10-12

Stephens GL, Ellis TD (2008) Controls of global-mean precipitation increases in global warming GCM experiments. J Clim 21:6141-6155

Sugiyama M, Shiogama H, Emori S (2010) Precipitation extreme changes exceeding moisture content increases in MIROC and IPCC climate models. Proc Natl Acad Sci 107:571-575

Taylor KE, Stouffer RJ, Meehl GA (2011) An overview of CMIP5 and the experiment design. Bull Am Meteorol Soc 93:485-498. doi:10.1175/BAMS-D-11-00094.1

Trenberth KE (2011) Changes in precipitation with climate change. Clim Res 47:123-138

Trenberth KE, Fasullo JT, Mackaro J (2011) Atmospheric moisture transports from ocean to land and global energy flows in reanalyses. J Clim 24:4907-4924. doi:10.1175/2011JCLI4171.1

Turner AG, Slingo JM (2009) Uncertainties in future projections of extreme precipitation in the indian monsoon region. Atmos Sci Lett 10:152-158

Vecchi GA, Soden BJ, Wittenberg AT, Held IM, Leetmaa A, Harrison MJ (2006) Weakening of tropical pacific atmospheric circulation due to anthropogenic forcing. Nature 441:73-76 
Volodin EM, Dianskii NA, Gusev AV (2010) Simulating present-day climate with the INMCM4.0 coupled model of the atmospheric and oceanic general circulations. Izvestiya Atmos Ocean Phys 46:414-431. doi:10.1134/S000143381004002X

Voldoire A, Sanchez-Gomez E, Salas y Mélia D, Decharme B, Cassou C, Sénési S, Valcke S, Beau I, Alias A, Chevallier M, Déqué M, Deshayes J, Douville H, Fernandez E, Madec G, Maisonnave E, Moine M-P, Planton S, Saint-Martin D, Szopa S, Tyteca S, Alkama R, Belamari S, Braun A, Coquart L, Chauvin F (2012) The CNRM-CM5.1 global climate model: description and basic evaluation. Clim Dyn. doi:10.1007/s00382-011-1259-y

Watanabe M, Suzuki T, O'ishi R, Komuro Y, Watanabe S, Emori S, Takemura T, Chikira M, Ogura T, Sekiguchi M, Takata K, Yamazaki D, Yokohata T, Nozawa T, Hasumi H, Tatebe H, Kimoto M (2010) Improved climate simulation by MIROC5: mean states, variability, and climate sensitivity. J Clim 23:6312-6335. doi:10.1175/2010JCLI3679.1

Wentz FJ, Schabel M (2000) Precise climate monitoring using complementary satellite data sets. Nature 403:414-416

Wentz FJ, Ricciardulli L, Hilburn K, Mears C (2007) How much more rain will global warming bring? Science 317:233-235

Willett KM, Jones PD, Gillett NP, Thorne PW (2008) Recent changes in surface humidity: Development of the HadCRUH dataset. J Clim 21(20):5364-5383

Wu P, Wood R, Ridley J, Lowe J (2010) Temporary acceleration of the hydrological cycle in response to a CO2 rampdown. Geophys Res Lett 37:L12705. doi:10.1029/2010GL043730

$\mathrm{Wu}$ T et al. (2012) The 20th century global carbon cycle from the Beijing Climate Center Climate System Model (BCC CSM). J Clim (in press)

Yukimoto S, Y A, Hosaka M, Sakami T, Yoshimura H, Hirabara M, Tanaka TY, Shindo E, Tsujino H, Deushi M, Mizuta R, Yabu S, Obata A, Nakano H, Ose T, Kitoh A (2012) A new global climate model of meteorological research institute: MRI-CGCM3-model description and basic performance. J Meteorol Soc Jpn (under preparation)

Zahn M, Allan RP (2011) Changes in water vapor transports of the ascending branch of the tropical circulation. J Geophys Res 116:D18111. doi:10.1029/2011JD016206

Zahn M, Allan RP (2012) Climate Warming related strengthening of the tropical hydrological cycle. J Clim. doi:10.1175/JCLI-D-12-00222.1

Zhang Y, Rossow WB, Lacis AA, Oinas V, Mishchenko MI (2004) Calculation of radiative fluxes from the surface to top of atmosphere based on ISCCP and other global data sets: refinements of the radiative transfer model and the input data. J Geophys Res 109:D19105. doi:10.1029/2003JD004457

Zhang ZS, Nisancioglu K, Bentsen M, Tjiputra J, Bethke I, Yan Q, Risebrobakken B, Andersson C, Jansen E (2012) Pre-industrial and mid-Pliocene simulations with NorESM-L. Geosci Model Dev Discuss 5:119-148. doi:10.5194/gmdd-5-119-2012 